Corrigendum

\title{
Corrigendum to "Analysis of the Power of Common Diagnostic Tools in the Management of Acute Pancreatitis"
}

\author{
Markus Nistal, ${ }^{1}$ Malalai Zoltani, ${ }^{2}$ Ansgar W. Lohse, ${ }^{2}$ Nicola Di Daniele $\left(\mathbb{D},{ }^{3}\right.$ \\ Manfredi Tesauro ${ }^{D},{ }^{3}$ and Andrea Pace ${ }^{2,4}$ \\ ${ }^{1}$ Sozialstiftung Bamberg-Medizinische Klinik II, 96049 Bamberg, Germany \\ ${ }^{2}$ Medizinische Klinik I, Universitaetsklinikum Hamburg-Eppendorf, 20246 Hamburg, Germany \\ ${ }^{3}$ Department of Internal Medicine, University of Rome Tor Vergata, Viale Oxford 81, 00133 Rome, Italy \\ ${ }^{4}$ Klinik für Gastroenterologie, Friedrich-Ebert-Krankenhaus, 24534 Neumünster, Germany \\ Correspondence should be addressed to Manfredi Tesauro; mtesauro@tiscali.it
}

Received 31 October 2017; Accepted 29 November 2017; Published 24 June 2018

Copyright ( 92018 Markus Nistal et al. This is an open access article distributed under the Creative Commons Attribution License, which permits unrestricted use, distribution, and reproduction in any medium, provided the original work is properly cited.

In the article titled "Analysis of the Power of Common Diagnostic Tools in the Management of Acute Pancreatitis" [1], the name of one of the authors was given incorrectly as Malai. The author's name should have been written as Malalai. The revised authors' list is shown above. Additionally, it should have been noted that Markus Nistal and Malalai Zoltani contributed equally to this work as joint first authors of the article.

\section{Authors' Contributions}

Markus Nistal and Malalai Zoltani contributed equally to this work.

\section{References}

[1] M. Nistal, M. Zoltani, A. W. Lohse, N. Di Daniele, M. Tesauro, and A. Pace, "Analysis of the power of common diagnostic tools in the management of acute pancreatitis," Gastroenterology Research and Practice, vol. 2014, Article ID 438697, 4 pages, 2014. 


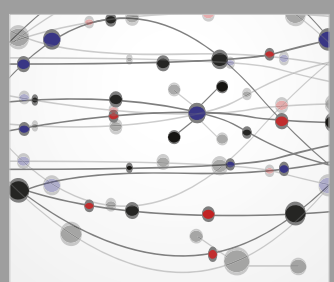

The Scientific World Journal
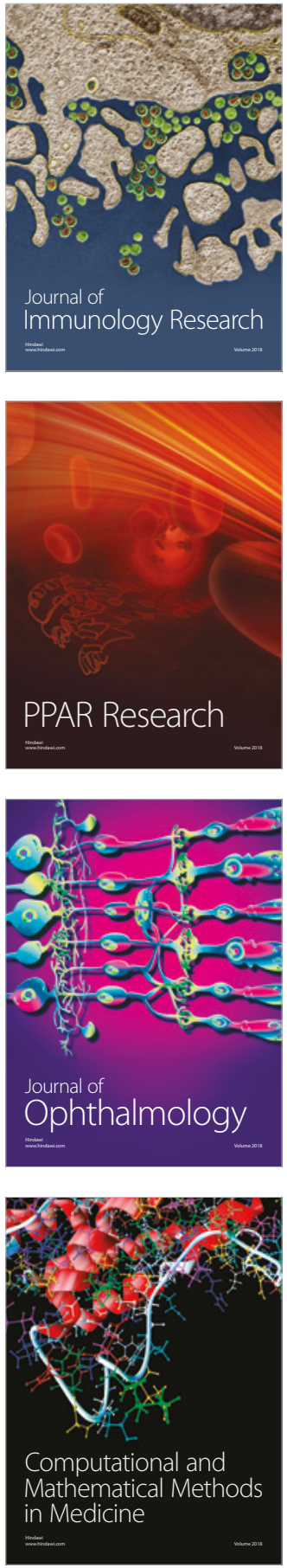

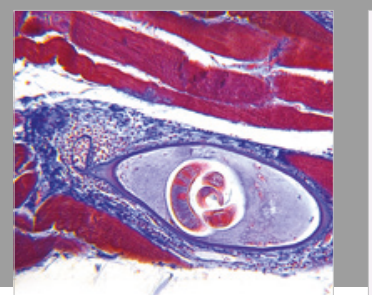

Gastroenterology Research and Practice

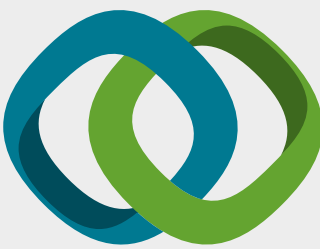

\section{Hindawi}

Submit your manuscripts at

www.hindawi.com
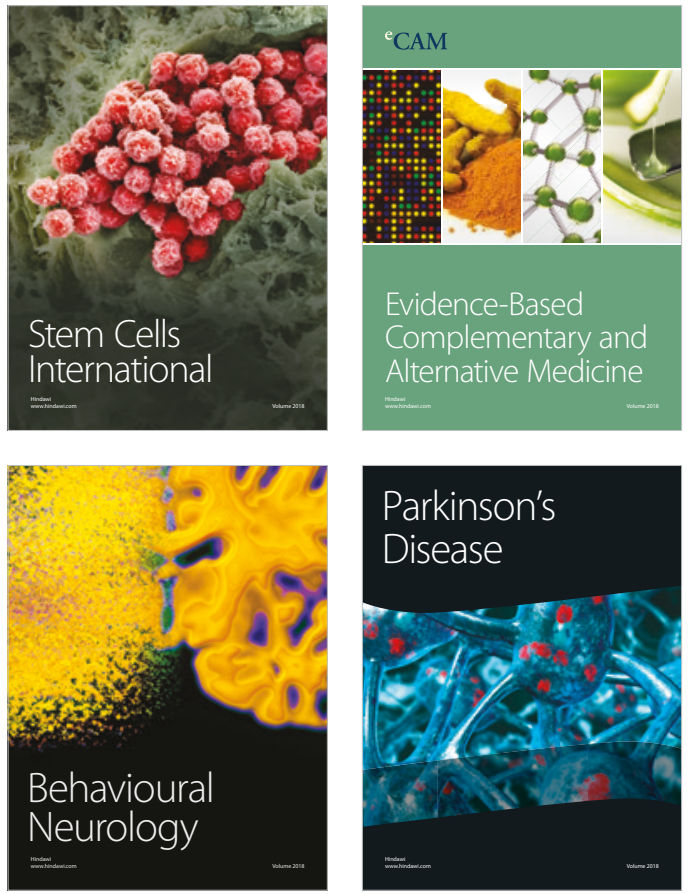

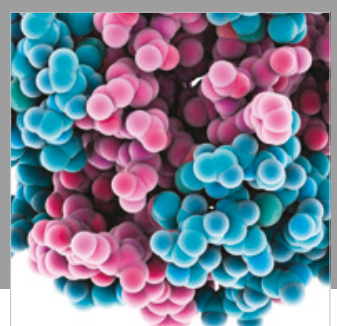

ournal of

Diabetes Research

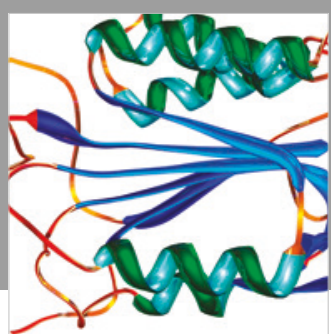

Disease Markers
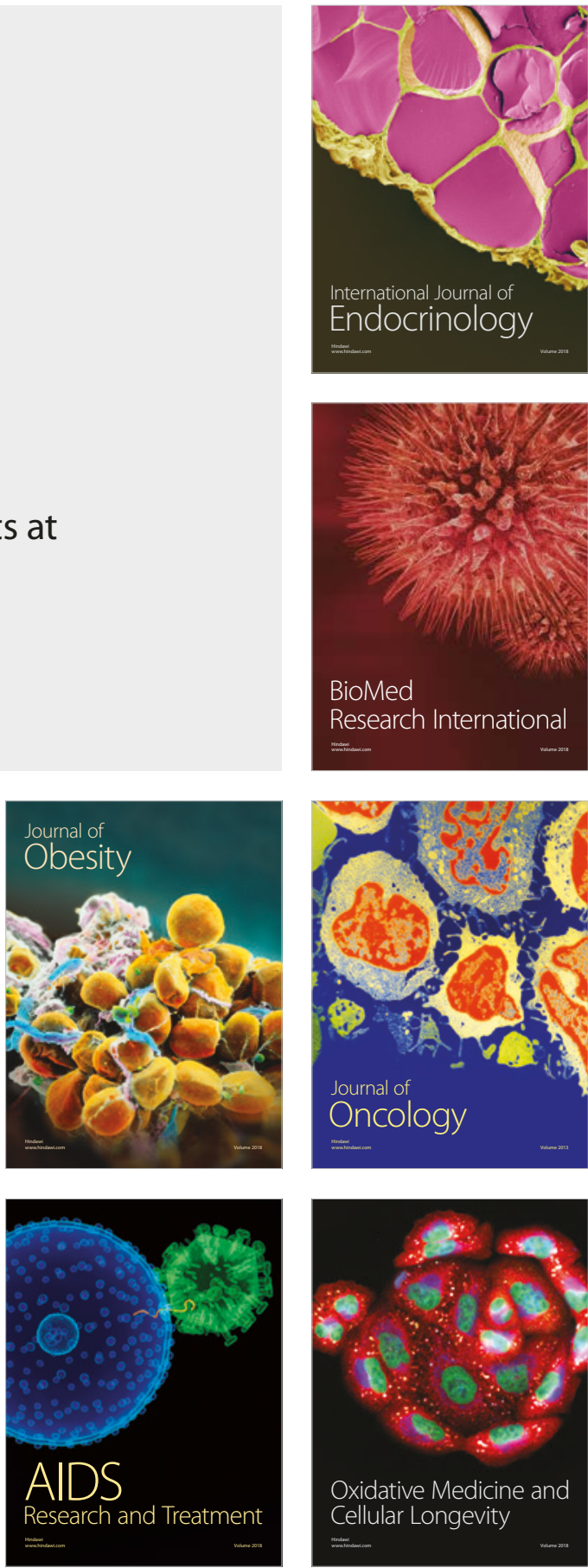